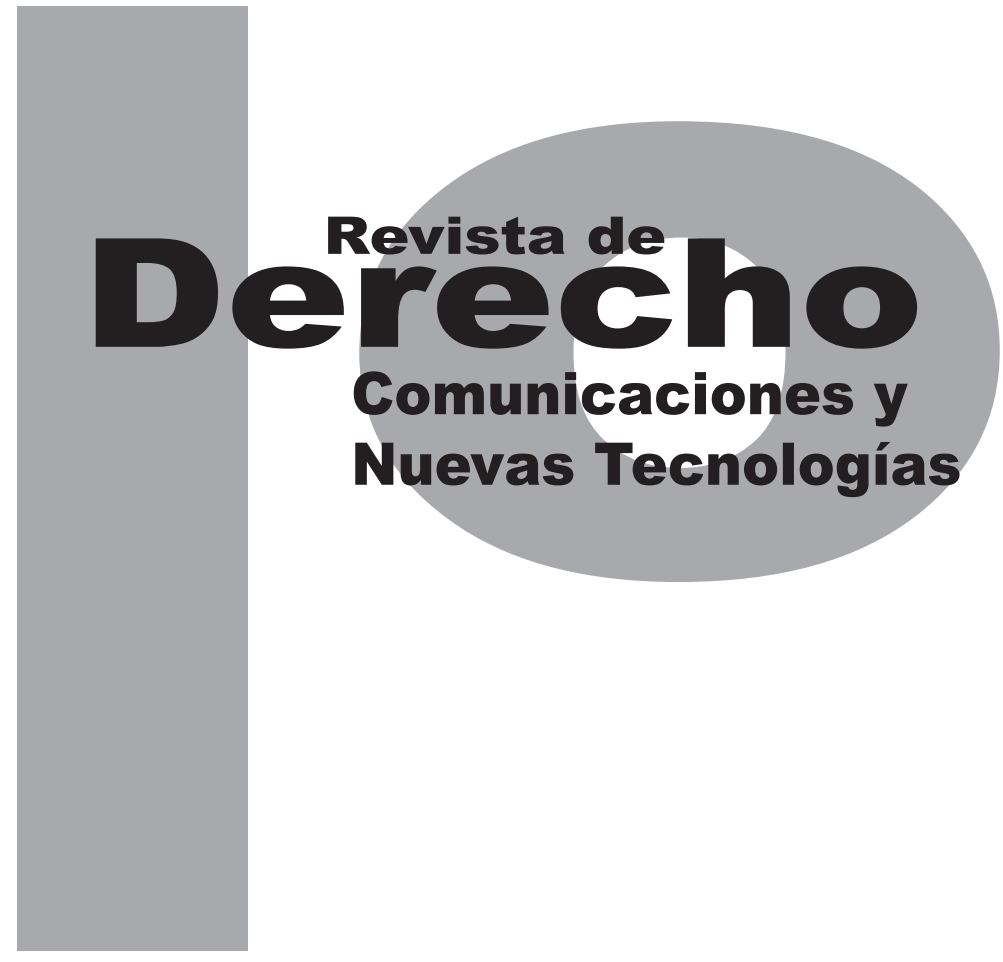

\title{
LÍMITES CONSTITUCIONALES A LA AUDIENCIA TELEMÁTICA EN EL PROCESO PENAL VENEZOLANO
}

\author{
Gustavo Adolfo Amoni ReVerón
}

Artículo de reflexión

DOI: http://dx.doi.org/10.15425/redecom.12.2014.10

\author{
Universidad de los Andes \\ Facultad de Derecho
}

Revista de Derecho, Comunicaciones y Nuevas Tecnologías

No.12, Julio - Diciembre de 2014. ISSN 1909-7786 


\section{Límites constitucionales a la audiencia telemática en el proceso penal venezolano}

\section{Resumen}

A fin de verificar si es jurídicamente válido acudir a la telemática en la ejecución de las audiencias procesales penales en Venezuela, se analizaron los tipos de audiencias previstas en el Decreto con Rango y Fuerza de Ley de Código Orgánico Procesal Penal, así como los derechos y deberes previstos para desarrollarlas, los principios que las informan, y, por último, las normas constitucionales que las limitan. Así, se concluyó que: 1. La regulación penal adjetiva no prevé normas generales o específicas que impidan la audiencia penal telemática; 2. Los derechos y deberes previstos para su cumplimiento pueden verificarse en formato telemático, sin violentar los principios procedimentales de ley; y 3. La audiencia penal telemática es constitucional, aunque con ciertos límites, donde destaca la voluntad del privado de libertad, quien deberá ser presentado de forma real ante un órgano jurisdiccional, cuando lo solicite.

Palabras clave: proceso penal telemático, inmediación, audiencia, Tecnologías de la Información y Comunicación (TIC), videoconferencia.

\section{Constitutional limitations to telematical hearing in the venezuelan criminal procedure}

\section{Abstract}

In order to determine the legal validity of the telematical hearing in the Venezuelan criminal procedure, it was necessary to analyze: the types of criminal hearings, the rights and duties provided to develop the principles that inform them, and finally, the constitutional rules that state the limits on this topic. In this order, the conclusion are: 1 . The criminal law does not provide general or specific rules prohibiting telematical criminal hearings; 2 . The rights and duties provided by law can be fulfilled using information and communication technologies without violating legal principles; and 3. Telematical criminal hearing is constitutional, but there are some limits. One of them is the will of the detained, who shall be submitted in real presence before a court, when requested.

Key words: telematical criminal procedure, immediacy, hearing, information and communication technology (ICT), videoconference.

\section{Limites constitucionais da audiência telemática no processo penal venezuelano}

\section{Resumo}

A fim de verificar se é juridicamente válido acudir à telemática na execução das audiências processuais penais na Venezuela, foram analisados os tipos de audiências previstas no Decreto com Rango e Força de Lei de Código Orgânico Processual Penal, assim como os direitos e deveres previstos para desenvolvê-las, os princípios que as informam, e, por último, as normas constitucionais que as limitam. Assim, concluiu-se que: 1. A regulação penal adjetiva não prevê normas gerais ou específicas que impeçam a audiência penal telemática; 2. Os direitos e deveres previstos para seu cumprimento podem ser verificados em formato telemático, sem violentar os princípios procedimentais de lei; e 3. A audiência penal telemática é constitucional, embora com certos limites, onde destaca a vontade do privado de liberdade, que deverá ser apresentado de forma real ante um órgão jurisdicional, quando for solicitado.

Palavras-chave: processo penal telemático, imediação, audiência, Tecnologias da Informação e Comunicação (TIC), videoconferência. 


\title{
Límites constitucionales a la audiencia telemática en el proceso penal venezolano*
}

\author{
Gustavo Adolfo Amoni Reverón ${ }^{* *}$
}

\section{SUMARIO}

I. INTRODUCCIÓN - II. LAS AUDIENCIAS EN EL DECRETO CON RANGO, VALOR Y FUERZA DE LEY DEL CÓDIGO ORGÁNICO PROCESAL PENAL DE 2012 (DLCOPP) - A. Tipos de audiencias - B. Compatibilidad de las normas del DLCOPP con la celebración virtual o telemática de las audiencias penales - III. PRINCIPIOS PROCESALES PENALES - A. Principios del procedimiento $y$ del proceso - B. Principios de los procedimientos en el DLCOPP - IV. DERECHOS Y GARANTÍAS CONSTITUCIONALES QUE PROMUEVEN Y LIMITAN LA AUDIENCIA PROCESAL PENAL TELEMÁTICA - A. Características del proceso jurisdiccional venezolano: artículo 257 - B. Derecho a la igualdad, en especial de quienes residen a mayor distancia de las sedes judiciales: artículos 2 y 21 - C. Derecho al bienestar y garantía del cumplimiento de los principios, derechos y deberes reconocidos y consagrados en la constitución: artículo 3 - D. Goce de los derechos humanos: artículo 19 - E. Primacía de los tratados sobre derechos humanos más favorables: artículo 23 - F. Deber de cumplir la constitución y nulidad de los actos que violen los derechos garantizados en ella: artículos 25 y 131 - G. Principio de legalidad: artículos 137 y 253 - H. Derecho de acceso a los órganos de justicia: artículo 26 - I. La libertad personal: artículo 44 (numeral 1) - J. Privacidad de las comunicaciones: artículo 48 y 60 - K. El debido proceso: artículo 49 - L. Derecho de acceso a la información: artículo 110 - V. CONCLUSIONES - Referencias

Cómo citar este artículo: Amoni Reverón, G. A. (Diciembre, 2014). Límites constitucionales a la audiencia telemática en el proceso penal venezolano. Revista de Derecho, Comunicaciones y Nuevas Tecnologías, 12. Universidad de los Andes (Colombia).

** Abogado de la Universidad de Carabobo, 2004. Especialista en derecho administrativo de la Universidad Católica Andrés Bello, 2011. Estudiante de la Especialidad en Derecho Procesal de la Universidad Católica Andrés Bello. Profesor de postgrado de la Universidad Católica Andrés Bello. Abogado auxiliar II en la Sala de Casación Penal del Tribunal Supremo de Justicia de la República Bolivariana de Venezuela. Correo electrónico: gustavoamoni@ hotmail.com 


\section{INTRODUCCIÓN}

Es una máxima de experiencia que la sociedad convive con las TIC. Partiendo de esa realidad, no parece adecuado ignorar su aplicación en toda actividad humana, que, por tal razón, adolece de problemas que pueden ser mejorados a partir de ellas.

En este ámbito se incluyen los procesos jurisdiccionales, en los que un inconveniente no poco frecuente es el retardo procesal, fenómeno del que se ha ocupado la doctrina, la legislación y la jurisprudencia, ofreciendo posibles soluciones desde diversas perspectivas.

Entre los motivos de ralentización en el ámbito procesal penal, destaca por su reiteración la incomparecencia del acusado, de la defensa o del representante del Ministerio Público, lo que genera el diferimiento, inclusive durante años, de la audiencia correspondiente.

De ahí que siendo la falta de asistencia a la sede jurisdiccional una de las razones de mayor incidencia en la prolongación de los procesos judiciales, deben ensayarse nuevas opciones para garantizar la presencia de las partes en el proceso de la manera más fácil, económica, cómoda y segura posible. Es aquí cuando surge el uso de las TIC, de vasta aplicación y aceptación en el ámbito de las relaciones privadas y cada vez más presentes en las relaciones jurídicas, tanto privadas como públicas.

Al respecto, es suficiente citar el correo electrónico, la videoconferencia y las trasferencias electrónicas de dinero para reconocer las posibilidades reales con las que se cuenta para optimizar el ejercicio de la jurisdicción en beneficio de los ciudadanos y de la misma administración de justicia.

$Y$ es que si diariamente se verifican relaciones a distancia, incluso jurídicas, faltan razones para actuar desconectados de la tecnología, en un rechazo injustificado hacia la telemática, disciplina científica que permitiría la intervención a distancia de cualquier sujeto en cumplimiento de la oralidad que informa el proceso penal, reduciendo costos y tiempo, situación que se hace más apremiante aun cuando el despacho judicial se ubica fuera del ámbito territorial de residencia o domicilio de cualquiera de los sujetos procesales cuya presencia se requiere en el tribunal.

No obstante, la posibilidad fáctica de utilizar las TIC no implica su validez jurídica, en especial porque la Constitución de la República Bolivariana de Venezuela (CRBV) consagra una serie de derechos y garantías fundamentales de aplicación directa en el proceso penal, cuya vulneración conllevaría la nulidad de lo actuado.

Por esta razón, se analizarán los límites constitucionales a las diversas modalidades de audiencias en el proceso penal, ejecutadas en formato telemático.

Para tal fin, se comenzará determinando las audiencias que prevé el Decreto con Rango, Valor y Fuerza de Ley del Código Orgánico Procesal Penal (DLCOPP), precisando los elementos que las 
identifican conforme a los derechos que pueden ejercer las partes en ellas y los principios que las informan.

Posteriormente, se fijará el método a seguir a fin de su ejecución telemática, culminando con la evaluación de la normativa constitucional que le sirve de fundamento y de límite.

\section{LAS AUDIENCIAS EN EL DECRETO CON RANGO, VALOR Y FUERZA DE LEY DEL CÓDIGO ORGÁNICO PROCESAL PENAL DE 2012 (DLCOPP)}

\section{A. Tipos de audiencias}

Previo a conocer las audiencias del DLCOPP, es oportuno aclarar que el Diccionario de la Lengua Española define la audiencia, en su primera acepción, como el "acto de oír las personas de alta jerarquía u otras autoridades, previa concesión, a quienes exponen, reclaman o solicitan algo", precisando en su octava acepción que se trata de una "ocasión para aducir razones o pruebas que se ofrece a un interesado en juicio o en expediente".

Desde la perspectiva del Derecho Procesal, la audiencia es un acto procesal oral mediante el cual las partes y sus representantes judiciales exponen sus alegatos sobre determinado asunto ante el órgano jurisdiccional.

A pesar de la definición general presentada, la audiencia no siempre es igual, y en el ámbito procesal penal, el DLCOPP prevé veintitrés (23) audiencias diferentes según el procedimiento 0 fase procesal que se esté ejecutando.

Así, en el procedimiento ordinario y el de juzgamiento por la perpetración de delitos menos graves (los cuales se unifican a partir de la audiencia de juicio oral y público), pueden enumerarse ocho (8) audiencias en fase preparatoria: 1. La audiencia para practicar o recibir la prueba anticipada (artículo 289); 2. La audiencia para poner fin a la investigación (295); 3. La audiencia de presentación (artículos 132, 236 y 356). Esta misma audiencia se celebrará en el caso de aprehensión por flagrancia pudiendo dar lugar al procedimiento abreviado u ordinario, según lo decida el tribunal a solicitud del Ministerio Público (artículo 373); 4. La audiencia de excepciones en fase preparatoria que puede tramitarse con presentación de pruebas 0 de mero derecho, según el caso (artículo 30); 5. La audiencia de cuestión prejudicial mediante la cual se resolverá tal cuestión ateniéndose para ello a las pruebas que, según la respectiva legislación, sean admisibles y hayan sido incorporadas por las partes (artículo 36); 6. La audiencia para la suspensión condicional del proceso a los efectos del otorgamiento o no de la medida (artículo 44); 7. La audiencia del procedimiento de suspensión condicional del proceso mediante la cual el juez verifica el total y cabal cumplimiento de todas las obligaciones impuestas, pudiendo decretar el sobreseimiento de la causa (artículo 46); y 8. La audiencia para determinar la procedencia de la revocación de la medida de suspensión del proceso (artículo 47). 
Adicionalmente, el DLCOPP prevé en la fase intermedia un (1) tipo de audiencia, la audiencia preliminar (artículos $309^{2}$ y 365) en la que no se plantearán cuestiones propias del juicio oral y público (artículos 312 y 368).

Por su parte, la ley adjetiva penal establece dos (2) audiencias durante el juicio oral. Estas son: 1. La audiencia de juicio (artículos $315^{3}$ y 373 ) en la que se recibirán y practicarán pruebas (artículos $321^{4}$ y 342, respectivamente), ${ }^{5}$ siendo posible recibir los órganos de prueba mediante el uso de tecnología audiovisual (artículo 323), con miras a la realización del debate probatorio (artículo 327), en cuyo desarrollo podrá ordenarse la detención de quien delinquiere, poniéndolo a la orden del Ministerio Público (artículo $32) ;$ y 2. La audiencia para dictar sentencia (artículos 159, 344 y 347).

Además, el DLCOPP prevé siete (7) audiencias en procedimientos especiales. ${ }^{6}$ Estas son: 1.

2 El artículo 312 DLCOPP prevé que: "Finalizada la audiencia el Juez o Jueza resolverá, en presencia de las partes", a la vez que el artículo 314 establece que "La decisión por la cual el Juez o Jueza admite la acusación se dictará ante las partes...”, exigencias que pueden interpretarse como presencia virtual, ya que la ley no discrimina al respecto, al igual que sucede con el deber de las partes de concurrir ante el juez de juicio (numeral 5, artículo 314).

3 Inclusive la consagración legal de efectuar el debate "total o parcialmente a puertas cerradas" (artículo 316) salva la posibilidad de acudir a la telemática, ya que lo único que excluye es la presencia del público en la sala de juicio.

$4 \quad$ El deber de concurrir al debate, previsto en los artículos 325 y 327 DLCOPP, no descarta que dicha intervención se efectúe a distancia.

5 En el caso de delitos menos graves, el artículo 370 DLCOPP prevé que la celebración del juicio oral y público se hará "ante un Tribunal", de donde no se niega el uso de las TIC.

6 Aunque el procedimiento para el juzgamiento de delitos menos graves es especial, no se incluyó en esta sección sino que se mantuvo junto al ordinario por tratarse del mismo tipo de audiencias que se celebra
La audiencia de antejuicio de mérito (artículo 379); 2. La audiencia de presentación en caso de detención cautelar en el procedimiento de extradición (artículo 387); 3. La audiencia de extradición ante la Sala de Casación Penal (artículo 390); 4. La audiencia conciliatoria en el procedimiento de acción dependiente de instancia de parte (artículo 400); 5. La audiencia de juicio en el procedimiento de acción dependiente de instancia de parte (artículo 404). En esta se debatirán los alegatos y pruebas promovidas oportunamente (numeral 4 del artículo 402); 6. La audiencia conciliatoria en el procedimiento de reparación de daños e indemnización de perjuicios derivados del delito (artículo 419); y 7. La audiencia para debatir sobre la reparación del daño y la indemnización en la que se discutirán oralmente los alegatos y pruebas que se incorporen al proceso (artículo 421).

Inclusive durante la ejecución de las sentencias están reguladas dos (2) audiencias: 1. La audiencia para resolver incidencias de ejecución con la posibilidad de debatir pruebas testimoniales y experticias (artículo 475); y 2. La audiencia para revisar medidas de seguridad, con periodicidad semestral o inferior (artículo 503).

Por último, en el ámbito recursivo, el DLCOPP prevé tres (3) audiencias. Se trata de: 1. La audiencia de apelación de autos en la que eventualmente se podrán debatir pruebas (artículo 442); 2. La audiencia de apelación de sentencias en la que, igualmente, se debatirán pruebas

en el procedimiento ordinario pero diferenciándose en razón de la cantidad de la pena. 
en casos precisos (artículo 448); y 3. La audiencia de casación que también es un escenario en el que se posibilita el debate probatorio en los términos restringidos de la ley (artículo 458).

Resumiendo lo expuesto, se concluye que la normativa reguladora de las audiencias citadas no excluye expresamente el uso de las tecnologías de información, ${ }^{7}$ normalmente llamadas Tecnologías de Información y Comunicación (TIC), sino que se refiere a la potestad del Ministerio Público, defensores públicos y del órgano jurisdiccional, así como también a las facultades de la víctima, acusado y defensores privados, de exponer y debatir únicamente argumentos en catorce (14) audiencias, así como también, además de tal participación argumentativa, deliberar sobre los elementos de convicción o pruebas, según corresponda, en las nueve (9) audiencias que así lo indican.

Aunado a ello, el DLCOPP tampoco contiene norma alguna de aplicación general que impida el uso de tales tecnologías; sin embargo, es preciso verificar cada una de las normas del DLCOPP a fin de delimitar la actividad que pueden desarrollar los sujetos procesales en las audiencias para luego analizar si pueden ejecutarse de forma virtual o telemática.

7 El numeral 17 del artículo 5 de la Ley de Infogobierno, de 2013, define las tecnologías de información, como "Tecnologías destinadas a la aplicación, análisis, estudio y procesamiento en forma automática de información".

\section{B. Compatibilidad de las normas del DLCOPP con la celebración virtual o telemática de las audiencias penales}

El artículo $1^{\circ}$ prevé que "Nadie podrá ser condenado sin un juicio previo, oral y público [...] ante un Juez o Jueza, o tribunal imparcial". En este precepto no se impone como única posibilidad de la oralidad ante el juez el hecho de acudir personalmente a la sede judicial, sino que pareciera que el debate también pudiera verificarse oralmente ante el juez mediante el uso de las TIC, como se verificará posteriormente ${ }^{8}$ y como se infiere del principio de "telematización" que inspira el Decreto con Fuerza de Ley Sobre Mensajes de Datos y Firmas Electrónicas de 2001 (DLMDFE), específicamente en cuanto al uso de mensajes de datos y firmas electrónicas en el ámbito jurídico privado o público, donde caber incluir su uso procesal. ${ }^{9}$

Así mismo, es importante destacar la Ley de Infogobierno de 2013, cuyo objeto es establecer los principios, bases y lineamientos que rigen el uso de las TIC en el Poder Público y el Poder Popular (artículo 1), sin excluir a la función jurisdiccional; de ahí que el principio de acceso por

8 Ver apartado B, referido a los "Principios de los procedimientos en el DLCOPP", del capítulo III titulado "Principios procesales penales".

9 Este instrumento jurídico otorga y reconoce eficacia y valor jurídico a la firma electrónica, al mensaje de datos y a toda información inteligible en formato electrónico, independientemente de su soporte material, atribuible a personas naturales o jurídicas, públicas o privadas (Art. 1), con lo cual resultan jurídicamente válidas las relaciones jurídicas telemáticas. Esta afirmación se refuerza al imponer al Estado el deber de adoptar las medidas necesarias para que los órganos públicos, entre ellos, los jurisdiccionales, puedan desarrollar sus funciones, utilizando los mecanismos descritos en este Decreto-Ley, como son los mensajes de datos y las firmas electrónicas (artículos 3, 6, 7 y 8). 
múltiples medios a la actuación del Poder Público (artículo 7), el principio de legalidad en la actuación electrónica (artículo 9), y los derechos de los particulares de relacionarse con el Poder Público mediante TIC, de forma no exclusiva y excluyente (artículos 6, 7 y 33), y, en consecuencia, usar TIC para dirigir peticiones, recibir notificaciones y acceder a los expedientes (artículo 8), sirven de fuente para validar las audiencias penales telemáticas, al constituir modos de interacción electrónica con el Poder Público, por órgano de los tribunales.

Por su parte, y continuando con la normativa procesal penal, la comparecencia ante la autoridad que la requiera (artículo 10), tampoco implica desconocer que es factible asistir ante la referida autoridad valiéndose de la tecnología.

Igualmente ocurre en el supuesto (del artículo 12) según el cual los jueces y demás funcionarios judiciales solamente podrán comunicarse con las partes o sus abogados, sobre los asuntos sometidos a su conocimiento, con la presencia de todas ellas. Aquí tampoco se observa impedimento alguno para la presencia plural, simultánea y telemática ante el juzgador.

De la misma manera, son actividades que pueden llevarse a cabo aplicando las TIC: el derecho de acceso a los órganos de administración de justicia penal (artículo 23); la presencia de las partes en el procedimiento de suspensión condicional del proceso a la que alude el artículo 44; el derecho del imputado a que se le informe de manera específica y clara acerca de los hechos que se le imputan (numeral 1 del artículo 127), a ser asistido desde los actos de investigación (numeral 3 del artículo 127), a ser asistido por un traductor o intérprete si no comprende o no habla el idioma castellano (numeral 4 del artículo 127), a ser impuesto o impuesta del precepto constitucional que lo exime de declarar y, aun en caso de consentir a prestar declaración, a no hacerlo bajo juramento (numeral 8 del artículo 127); el derecho a solicitar ante el tribunal de la causa el sobreseimiento, conforme a lo establecido en este Código (numeral 11 del artículo 127); el derecho a ser oído en el transcurso del proceso cuando así lo solicite (numeral 12 del artículo 127), e, inclusive, el derecho a presentarse directamente ante el juez con el fin de prestar declaración (numeral 6 del artículo 127).

También es posible cumplir por medios electrónicos con la identificación del imputado e interrogarlo conforme al artículo 128 DLCOPP; recibir la declaración del imputado y ser interrogado por el fiscal y el defensor, quienes podrán dirigir al imputado las preguntas que consideren pertinentes, obteniendo la respuesta verbalmente (artículo 134).

Inclusive, cuando el artículo 135 DLCOPP prevé que la declaración del imputado se hará constar en un acta que firmarán todos los que hayan intervenido, previa lectura, pareciera que la presencia personal es inevitable, no obstante, la misma norma permite que si el imputado se rehusare a suscribirla, se expresará el motivo, manteniéndose la validez de la declaración.

Es importante destacar que el artículo 138 DLCOPP prevé que en caso de ser varios los im- 
putados, sus declaraciones serán tomadas una tras la otra, sin permitirles que se comuniquen entre sí hasta la terminación de estas, lo cual tampoco execra a la telemática de las audiencias penales.

Por su parte, el artículo 141 DLCOPP establece que el nombramiento del defensor no está sujeto a ninguna formalidad, y puede efectuarse por cualquier medio, donde cabría incluir los telemáticos, por lo que pudiera efectuarse a distancia. Sin embargo, el defensor deberá acudir al tribunal a fin de estampar su firma en actas, ya que, inclusive, la juramentación sería válida en formato virtual.

Tampoco se observa obstáculo para revocar a distancia al defensor (artículo 144) y nombrar uno nuevo (artículo 145); para que el consultor técnico presencie las experticias (artículo 150); y para la intervención de los jueces, del secretario de la sala, del fiscal y de los abogados, usando togas (152).

Inclusive, el artículo 153 DLCOPP establece que toda acta será suscrita por los intervinientes, salvo que alguno no pudiera o quisiera firmar, en cuyo caso se dejará constancia de ese hecho. En estos últimos supuestos puede encuadrarse la intervención a distancia en el proceso penal.

Así mismo, al establecer el artículo 155 DLCOPP la comparecencia obligatoria del testigo, experto e intérprete regularmente citado en el lugar, día y hora establecidos, pareciera válido que el juez disponga que se traslade por medio de la fuerza pública a cualquier lugar con conexión a Internet, computadora, micrófono, altavoz y cámara para estar en su presencia de forma virtual o telemática, garantizándose el ejercicio de los derechos y garantías constitucionales de las partes. ${ }^{10}$

En caso de inasistencia justificada al debate, el juez los examinará donde se encuentren, y en el supuesto de encontrarse en lugar distinto al del juicio, o tratarse de personas que no tienen el deber de concurrir a prestar declaración, el juez avisará al juez competente para que los examine, ordenándose en ambos casos, por cualquier medio tecnológico audiovisual, la recepción y reproducción del acto, y las partes podrán participar en él (artículo 323).

En cuanto a la comparecencia de las víctimas, expertos, intérpretes y testigos a la que se refiere el artículo 169 DLCOPP, tampoco se advierte la imposibilidad de su materialización telemática, destacando la norma en referencia que si el testigo reside en un lugar lejano a la sede del tribunal y no dispone de medios económicos para trasladarse, se dispondrá lo necesario para asegurar la comparecencia, la cual, se reitera, no excluye expresa o tácitamente su ejecución virtual. ${ }^{11}$

10 El artículo 212 DLCOPP establece: "Si el o la testigo no se presenta a la primera citación, se le hará comparecer por medio de la fuerza pública".

11 El artículo 211 DLCOPP prevé: "Si el o la testigo reside en un lugar lejano a la sede del tribunal y carece de medios económicos para trasladarse, quien lo promueva, dispondrá de los medios necesarios para asegurar la comparecencia y podrá contar con la colaboración de los órganos del sistema de justicia". 
En materia de nulidades, el artículo 174 DLCOPP estatuye que los actos cumplidos en contravención o con inobservancia de las condiciones previstas en este Código, la CRBV, las leyes, tratados, convenios y acuerdos internacionales suscritos y ratificados por la República, no podrán ser apreciados para fundar una decisión judicial, salvo que el defecto haya sido subsanado o convalidado.

De la lectura de la norma citada pudiera pensarse que la presencia ante el juez a la que se refieren las normas procesales bajo análisis es siempre física tangible, por lo que la presencia virtual quedaría excluida, sin embargo, en caso de comprobarse si los aspectos por los que se exige la presencia física en la sede jurisdiccional en cumplimiento del principio de inmediación pueden cumplirse a cabalidad en formato electrónico, no cabrían razones para la nulidad.

En este mismo sentido, aunque el artículo 175 DLCOPP prevé como nulidades absolutas aquellas concernientes a la intervención, asistencia y representación del imputado, en los casos y formas que establezca el ordenamiento jurídico de rango constitucional o legal, la participación telemática en el proceso sería anulable en caso de impedir ejercer alguna de tales actividades, pero no por el simple hecho de la comparecencia virtual.

Por su parte, actividades como el deber de concurrencia del testigo ante el juez, previsto en el artículo 208 DLCOPP; la declaración de los sujetos excluidos del deber de comparecer, autorizados para declarar en el lugar donde cumplen sus funciones o en su domicilio (artículo 209); el interrogatorio que se le practicará al testigo para identificarlo (artículo 213); el traslado del tribunal para tomar la declaración del testigo que tenga impedimento físico para comparecer (artículo 215); ${ }^{12}$ el reconocimiento del imputado (artículos 217 y 218); el reconocimiento de objetos (artículo 220); el informe oral de los peritos en la audiencia (artículo 225);13 el deber de concurrir en caso de prueba anticipada (artículo 289); las declaraciones de las partes (artículo 330); ${ }^{14}$ la comunicación con el defensor sin que se suspenda la audiencia (artículo 332); la declaración por separado de los testigos (artículo 338); la juramentación e interrogatorio de testigos y expertos (artículo 339) y comparecencia por la fuerza pública (artículo 340); el reconocimiento efectuado por testigos y expertos al que se refiere el artículo 341; la discusión final y cierre previstos en el artículo 343; la admisión de la acusación de los procedimientos de delitos menos graves ante las partes (artículo 369); y el deber de los alguaciles de mantener el orden en la Sala de Audiencia (artículo 511), ${ }^{15}$ son actua-

12 Norma que debe complementarse con el artículo 323.

13 El 23 de julio de 2014 se publicó nota de prensa en la página de Internet del Tribunal Supremo de Justicia, informando que: "el sistema de videoconferencias será implementado en los juzgados de juicio en materia penal, pero la idea es extenderlo a tribunales de ejecución ordinarios, violencia contra la mujer y responsabilidad penal del adolescente. Además, que, de forma progresiva, se implemente en los diferentes estados del país" (Recuperado de: http://www.tsj.gov.ve/informacion/ notasdeprensa/notasdeprensa.asp?codigo=11970).

14 Hasta en el caso previsto en el artículo 331 DLCOPP, referido al alejamiento de la sala de audiencias de los imputados que no estuvieren declarando, puede interpretarse por alejamiento su desconexión temporal del sistema de videoconferencia, logrando que esta norma no constituya impedimento para la audiencia virtual.

15 Este precepto puede entenderse como la potestad de mantener el orden del público presente cuando los demás intervinientes lo hicieren a distancia. 
ciones cuya materialización telemática no está proscrita ni luce imposible en la práctica.

No obstante, se dificulta la audiencia virtual cuando la norma exige levantar un acta firmada por el imputado donde obliga a no ausentarse del ámbito de competencia territorial del tribunal (artículo 246), ${ }^{16}$ y un acta firmada por los integrantes del tribunal y por las partes en la que se dejará constancia del registro efectuado respecto de todo lo acontecido en el desarrollo del juicio oral y público (artículo 317). Sin embargo, esta situación no impide la audiencia virtual, puesto que el acta puede enviarse con el alguacil hasta el lugar donde se preste la declaración para recoger la firma del interviniente o en caso de rendirse la declaración desde una sede judicial, el órgano comisionado al efecto se encargaría de levantar el acta correspondiente. A pesar de tales posibles soluciones, el artículo 153, ya citado, resuelve este asunto al establecer que si alguno de los intervinientes en una audiencia no puede o no quiere firmar el acta que se levantará al efecto, se dejará constancia de ese hecho. En caso de una audiencia telemática, quien declara no puede suscribir el acta en papel mediante firma autógrafa, por lo que tal supuesto puede considerarse incluido en la norma comentada, resultando válida el acta sin la firma del declarante a distancia.

En lo que respecta a las facultades jurisdiccionales de limitar el tiempo del uso de la palabra

16 En este caso, el imputado puede firmar en el lugar desde el que preste declaración telemática ante el tribunal, siendo trasladado dicho documento a la sede judicial por un funcionario auxiliar de investigación penal, al igual que ocurre en el caso de la fianza que deben firmar los que la presten (artículo 247). a quienes intervengan durante el juicio, fijando límites máximos igualitarios para todas las partes, o interrumpiendo a quien haga uso manifiestamente abusivo de su facultad (artículo 324), se trata de una potestad igualmente ejercitable en una eventual audiencia virtual.

Del mismo modo, en un entorno virtual, resultaría posible ejercer las facultades disciplinarias destinadas a mantener el orden y decoro durante el debate y, en general, las necesarias para garantizar su realización eficaz (artículo 324), así como ordenar la detención de quien delinquiere durante el debate (artículo 328), aunque el lugar desde donde se emita la declaración y la presencia de un funcionario serán elementos altamente influyentes en la aplicación efectiva de tal potestad.

En resumen, durante las diferentes audiencias que se verifiquen en el proceso, las partes y los abogados defensores o asistentes (numerales 3 y 8 del artículo 127), testigos, expertos e intérpretes (numeral 4 del artículo 127) deberán interactuar de forma oral y pública ante el tribunal (artículo 1) las veces que el juez lo requiera (artículo 10), quien además tiene la potestad de comunicarse con dichos sujetos procesales en su conjunto (artículos 12, numeral 1 del 127 y 369) y de imponer orden en la sala de audiencias (artículos 324, 328 y artículo 511).

Durante el desarrollo del proceso, las partes, los abogados defensores y asistentes, testigos y expertos podrán y/o deberán comunicarse con el tribunal para declarar (argumentar, ejercer defensas, etc.) y ser interrogados, según corres- 
ponda (numerales 8, 11 y 12 del artículo 127; artículos 128, 134, 138, 209, 213, 218, 220, 225, 330, 338, 341 y 343). Así mismo, el acusado podrá nombrar, revocar y volver nombrar hasta tres (3) defensores (artículos 141, 144 y 145), además de comunicarse con su defensor sin que se suspenda la audiencia (artículo 332).

A fin de cumplir con los actos referidos, deben tener acceso a los órganos de administración de justicia penal (artículo 23); es decir, actuar en su presencia (artículos 44; numeral 6 del artículo 127; 150, 155, 323, 169, 175, 208, 215, $323,217,289$ y 331), inclusive por la fuerza pública (artículo 340).

De todo ello se levantarán actas firmadas por los intervinientes (artículos 135, 153, 246, 247 y 317), salvo que no quisieran o pudieran hacerlo (artículos 135 y 153).

Conforme a lo expresado, el DLCOPP establece una serie de actos de comunicación bidireccionales, entre el tribunal y los sujetos procesales a quienes la ley les reconoce cargas, derechos, deberes y obligaciones, donde el juez y el alguacil gozan de potestades disciplinarias respecto de los presentes en la sala de audiencias. Tales actuaciones serán documentadas en actas firmadas por los presentes, salvo las excepciones de ley.

Para determinar si cada uno de esos actos en audiencia puede cumplirse mediante la telemática, garantizando los derechos, deberes, cargas y obligaciones ejercitables en su desarrollo, se especificarán los principios que impone el mismo DLCOPP para la materialización de las audiencias procesales penales.

\section{PRINCIPIOS PROCESALES PENALES $^{17}$}

\section{A. Principios del procedimiento $y$ del proceso}

La celebración de las veintitrés (23) modalidades de audiencias enumeradas arriba están sometidas a los principios que informan los procedimientos penales en Venezuela: oralidad, publicidad, inmediación y concentración, así como a los principios procesales de contradicción e igualdad de la partes, de los cuales, a fin de determinar la constitucionalidad de su realización telemática, solamente interesan los primeros, por una razón fundamental: el uso de las TIC atañe directamente al procedimiento en tanto que forma de concreción del proceso y no a este último.

Y es que el procedimiento ${ }^{18}$ denota las formalidades previstas por el ordenamiento jurídico

17 El desarrollo del presente título se elaboró adaptando un artículo anterior: Amoni, G. (2012). De los procedimientos judiciales orales a los electrónicos. Fodertics, estudios sobre Derecho y Nuevas Tecnologías. España: Andavira.

18 El procedimiento es "el conjunto de formas solemnes reguladas por la ley, por medio de las cuales actúan los tribunales" (Montero Aroca, 2004 , p. 18). En el mismo sentido, "el procedimiento es la manera en que exteriormente se cumplen los actos o actividades tendentes a lograr la tutela que el proceso promete" (Ortiz-Ortiz, 2004, p. 442). Por su parte, y manteniendo la misma línea de pensamiento, PrietoCastro (1989, p. 38) considera que el procedimiento "indica el lado externo de la actividad procesal"; mientras que en criterio de Fairén Guillén (1990, p. 45) es "La vía para constituir la satisfacción [jurídica]... en su cara externa", del mismo modo que para Guasp (1962, p. 18) es "la forma extrínseca de manifestarse la figura, no su verdadera e íntima sustancia”. 
para que pueda desarrollarse el proceso, ${ }^{19}$ de ahí que el uso procesal de las TIC, concretamente la celebración telemática de las audiencias penales, importa de forma indirecta al proceso, el cual "se desarrolla formalmente a través de un procedimiento" (Montero Aroca, 2004, p. 295), que puede ser escrito, oral e inclusive electrónico.

Esta diferenciación cuenta con respaldo constitucional ya que en el artículo 257 se refiere "al proceso" como un instrumento fundamental para realizar la justicia e impone que las leyes procesales establecerán la simplificación, uniformidad y eficacia de los trámites y adoptarán “un procedimiento" breve, oral y público, sin sacrificar la justicia por la omisión de formalidades no esenciales.

Por esta razón, resulta innecesario referirse a los principios procesales de contradicción (artículo 18, DLCOPP) e igualdad (artículo 12, DLCOPP) (Montero Aroca, 2004, p. 295), circunscribiéndose el análisis a los principios procedimentales expresados con anterioridad, sobre los que influye el uso de las TIC.

19 "El proceso es el conjunto de relaciones jurídicas que se produce cuando la acción de los particulares se pone en contacto con la jurisdicción ejercida por el Estado para el conocimiento, decisión y ejecución de los intereses y derechos tutelados por el ordenamiento jurídico" (Ortiz-Ortiz, 439). Considerando también al proceso como un fenómeno diferenciado del procedimiento, Fairén Guillén (p. 45) lo define como "una serie de situaciones jurídicas contrapuestas de las partes, integradas por posibilidades, expectativas, perspectivas y cargas (naturaleza jurídica), concatenadas entre sí de modo ordenado (estructura) y destinada a la consecución de satisfacciones jurídicas (función), bajo la dirección del Juez estatal"; a la vez que, según Calamandrei (1943, p. 267), "se resume en sustancia en una continuada colaboración de las partes dirigidas a convertir en concreto y actual, fijando límites, el deber del órgano judicial de hacer justicia en interés público".
Ahora bien, para comenzar el examen de tales principios es útil precisar qué se entiende por principios. En criterio de Robert Alexy "son normas que ordenan que algo sea realizado en la mayor medida posible, de acuerdo con las posibilidades fácticas y jurídicas. Por ello, los principios son mandatos de optimización" (Robert, 2007, p. 349).

Por su parte, Milagros Otero Parga se refiere a los principios como cláusulas generales diferentes a las reglas que sí gozan de contenido concreto. Los principios son menos generales que los valores pero sin llegar a la concreción de las reglas, las cuales se derivan de los principios, puesto que su "interés se centra en la explicitación de contenidos", específicamente, de contenidos de las reglas (Otero, 1999, p. 24).

Es así como los principios deben ser ejercidos progresivamente a partir de un nivel mínimo, determinable conforme a las características socioeconómicas y legales del ordenamiento jurídico, cuyo desconocimiento supondría la desaparición del principio. De allí la importancia de precisar el contenido de los cuatro (4) principios enumerados anteriormente, para establecer si permiten el uso de las TIC.

\section{B. Principios de los procedimientos en el DLCOPP}

1. Principio de oralidad: exige que el juicio sea oral y solamente se aprecien las pruebas incorporadas en la audiencia (artículo 14 DLCOPP).

La exigencia aludida no supone un procedimiento totalmente oral sino predominantemente oral 
(Montero, 2004, p. 382). Por ello, tanto en el procedimiento escrito como en el oral puede haber actos orales que se transcriban a los fines de mantener un memorial del proceso (RengelRomberg, 2007, p. 179), se trata de la protocolización, que consiste justamente en llevar a escrito las actuaciones orales, sin que ello le quite el carácter de oral al procedimiento, ya que se trata de un acto que se originó en este formato (Puppio, 2001, p. 143).

El principio de oralidad implica que se debe sentenciar, únicamente, con base en el material procesal incorporado y debatido de manera oral $^{20}$ a pesar de que la pretensión y la contestación se hayan presentado por escrito (Montero, 2004, p. 383).

En todo proceso, la oralidad puede ser, en efecto, principal, si priman las formas orales al momento de la intervención de las partes, testigos, peritos y demás sujetos procesales y, en especial, si el juez debe decidir con fundamento en lo debatido de modo oral y no con base en lo escrito; pero también puede ser secundaria, si prima la escritura como fuente de juzgamiento (Pérez, p. 130).

Lauría, C. (2000) "La prueba en el juicio oral". La aplicación efectiva del COPP, terceras jornadas de Derecho Procesal Penal. Caracas: UCAB, p. 165; Pérez, E. (2004). Los recursos en el proceso penal venezolano. Valencia, Venezuela: Vadell hermanos, p. 130; RengelRomberg, A. op. cit., p. 178; Salazar, R. (2001). Principios informadores del nuevo proceso penal. Primeras Jornadas de Derecho Procesal Penal, el nuevo proceso penal. Caracas: UCAB, p. 40; Schorbohm, H. y Lossing, N. (1995). El Proceso penal, principio acusatorio y oralidad en Alemania. Propuestas para la reforma del proceso penal venezolano. Barquisimeto: Colegio de Abogados del Estado Lara, p. 44; Vecchionacce, F. (2001). El juicio Oral y la posición jurídica del imputado. Primeras Jornadas de Derecho Procesal Penal, el nuevo proceso penal, Caracas: UCAB, pp. 229 y 232.
Incorporando TIC a las audiencias del proceso penal es posible cumplir con este principio, ya que las partes, testigos, peritos e intérpretes pueden comunicarse oralmente con el juzgador y viceversa, e inclusive entre ellos, como sucede con la videoconferencia.

2. Principio de publicidad: Implica que el juicio oral sea público (artículo 15 DLCOPP).

La publicidad procesal es el derecho que tienen los individuos y la sociedad de ser informados acerca del desarrollo de un proceso judicial "por cualquier medio, incluido los medios de comunicación social" (Vecchionacce, p. 234), entre ellos, Internet.

En el procedimiento oral, la publicidad se logra con la presencia de las personas en la audiencia, mientras que en el escrito se cumple con la posibilidad universal de acceder al expediente y de obtener copias simples (Puppio, p. 151).

La finalidad de este principio es que los asistentes a la audiencia conozcan cómo y por qué se juzgó de una manera determinada (Salazar, p. 41)además de ofrecer mayores garantías de transparencia en la actuación judicial.

La publicidad puede ser de dos tipos: relativa, si solo pueden conocer el proceso las partes, como ocurre, a título de ejemplo, en la fase preparatoria del proceso penal; o absoluta, si todos los ciudadanos pueden acceder a su conocimiento como ocurre en el proceso civil o en la fase de juicio del proceso penal. 
Para que haya una verdadera publicidad, pudiera pensarse que un proceso judicial requiere tramitarse de modo oral, e incluso que "la publicidad solo es posible con plenitud si el proceso se realiza en acto concentrado y oral" (Montero, 2004, p. 360), lo que constituye una garantía "de que el público se entere de lo que sucede en el proceso penal" (Vecchionacce, p. 232).

En este caso, si la audiencia virtual se realiza en una sala de audiencia a la que puede ingresar quien lo deseare según la capacidad del recinto y el tipo de proceso que se esté llevando a cabo, al proyectarse en un pantalla adecuada al espacio y reproducirse con un sistema de sonido con capacidad apta para el mismo lugar en que se presenta la declaración o debate telemático, además de una velocidad de conexión de Internet suficiente, se cumpliría con el referido principio de publicidad, al igual que si el sujeto procesal estuviese presente.

3. Principio de concentración: Obliga a decidir en el menor número de audiencias posible (artículo 17, DLCOPP).

Este principio impone que los actos procesales se ejecuten, en la medida de lo posible, de modo íntegro en una audiencia, mas no de manera fraccionada en diversas actuaciones, ya que el paso del tiempo hace que se pueda perder seguridad en las pruebas ${ }^{21}$ además de que "conspira contra la memoria" 22 , y dado que

21 Schorbohm, H. y Lossing, N. op. cit., p. 46; Puppio, V. op. cit, p. 145; Vecchionacce, F. op. cit, p. 538 y Rengel-Romberg, A. op. cit, p. 180.

22 Salazar, R. op. cit, p. 43. En el mismo sentido: Pérez, E. op. cit, p. 130 y Vecchionacce, F. op. cit, p. 229. el juez sentenciará con los elementos que vaya recabando a lo largo del juicio, mientras más tiempo transcurra desde el debate hasta que se dicte sentencia, será más difícil para el juez fundar su decisión con base en los argumentos y pruebas presentados en la audiencia.

El principio de concentración no se descarta con la incorporación de la telemática a la celebración de las audiencias procesales penales, por el contrario, se garantiza en mayor medida al evitar los traslados hasta la sede judicial, particularmente en las audiencias de apelación y casación, respecto de quienes residen o están domiciliados lejos de las infraestructuras judiciales correspondientes. Lo mismo sucede en los casos de audiencias con detenidos, quienes pudieran declarar desde el lugar de reclusión donde estuvieren, evitando el tan difícil traslado.

4. Principio de inmediación: ${ }^{23}$ Con la oralidad, devienen otros principios, primordialmente la inmediación. Puesto que "el ser escuchado como acto procesal, el auditare,... ciertamente requiere inmediación" (Zerpa, 2007, p. 159), principio que impone a los jueces el deber de observar ininterrumpidamente el debate y la incorporación de las pruebas de las que obtiene su convencimiento (artículo 16, DLCOPP).

Este principio exige que el juez sentencie con fundamento en hechos y pruebas percibidos

23 Esta acápite constituye una adaptación de dos trabajos previos sobre el tema: Amoni, G. (2013). El uso de la videoconferencia en cumplimiento del principio de inmediación procesal. Revista IUS, 31, Puebla: Instituto de Ciencias Jurídicas de Puebla; y Amoni, G. (2014). Análisis jurisprudencial sobre la prueba de testimonial mediante videoconferencia en Venezuela. Fodertics II: Hacia una justicia 2.0, España: Ratio legis. 
por él mismo. ${ }^{24}$ Así, el juez conocerá en persona lo que dice quien esté declarando, bien sea testigo, experto o las partes, aunado a lo que manifiesten mediante sus gestos y su mirada (Salazar, p. 41).

Tal conocimiento se hace imposible en caso de que el juez delegare a terceros funciones exclusivas suyas como interrogar y evacuar pruebas, ${ }^{25}$ además de dificultar que el juez pueda, inclusive, delegar el dictamen de la sentencia como pudiera ocurrir fácilmente en el procedimiento escrito.

Ahora bien, el principio de inmediación está constituido por tres aspectos: la proximidad entre el juez y lo que evaluará o a quienes evaluará; la inexistencia de intermediarios, bien fueren cosas o personas (Devis Echandía, 1993, p. 129); $y$, la bilateralidad o bidireccionalidad (Garderes, 2002, p. 744) de donde derivan dos tipos de inmediación: 1. La pasiva, que supone la posibilidad del juzgador de percibir directamente la pruebas, por ejemplo, la declaración de quien depone en el proceso pero sin poder intervenir; y 2. La activa, que consiste en la percepción e intervención directa en el conocimiento de las pruebas por parte del juzgador, en especial, en la intervención de los sujetos procesales a los fines de interrogarlos, aclarar dudas y conducir el debate.

En consecuencia, es necesario determinar si el hecho de que el declarante se encuentre distan-

24 Schorbohm, H. y Lossing, N. op. cit, p. 45 y Rengel-Romberg, A. op. cit, p. 182

25

Schorbohm, H. y Lossing, N. op. cit, p. 51; y Puppio, V. op. cit, p. 145. te del juzgador constituye un obstáculo para la celebración de audiencias procesales penales telemáticas, ya que, por una parte, al estar lejos se descarta el requisito de la proximidad real, dado que no se rinde la declaración directamente ante él sino a través de una pantalla y la voz será reproducida mediante un sistema de sonido, lo que elimina, por otra parte, el requisito de la percepción sin intermediación.

Para responder esta pregunta es necesario determinar cuál es el elemento fundamental que la proximidad y la prohibición de intermediación imponen a los fines de que el juzgador obtenga el convencimiento necesario para sentenciar.

En cuanto a la proximidad, es definida como la cualidad de próximo, y esto a su vez, significa "cercano, que dista poco en el espacio o en el tiempo". ${ }^{26}$ Para que exista inmediación es necesario que el juez y quien declara estén ubicados uno cerca del otro para que la declaración pueda ser percibida por el administrador de justicia directamente, y aquí surge el segundo aspecto: sin intermediarios, de manera que el tribunal pueda formarse una decisión de la observación y escucha del propio declarante, de "primera mano" y no tergiversada por la representación que pudieran efectuar terceras personas o cosas.

En consecuencia, se requiere que el juez y el declarante estén cerca para observar y escuchar directamente lo que sucede, cómo sucede y dónde sucede, pues esta es la forma habitual como las personas se relacionan, aunque ello

Recuperado de: http://lema.rae.es/drae/?val=pr\%C3\%B3ximo 
no impide que la misma percepción personal e inmediata pueda generarse mediante la videoconferencia.

Es decir, si se interpreta el principio de la inmediación procesal atendiendo a los avances tecnológicos (Alves, Alves y Pereira, 2011, p. 44) con los que se conviven en la actualidad, será posible la recepción probatoria en garantía del referido principio, dado que esta tecnología constituye un medio para acercar en tiempo real a personas alejadas geográficamente y así permitir su interacción audiovisual, que es en definitiva lo que inspira al principio de inmediación, aunque no se haya pensado en la videoconferencia al redactar la ley (Landoni, 2002, p. 751).

El uso adecuado de la videoconferencia requiere, como se dijo antes, que se disponga de alta calidad técnica en la conexión (Landoni, 2002, p. 749) a Internet, para que la comunicación sea fluida, sin interrupciones extensas y reiteradas que impidan equiparar la presencia virtual a la real. Además, es indispensable que los equipos que conforman los recursos audiovisuales permitan que el juez y los demás sujetos procesales se observen y escuchen con detalle, al mismo momento en que se producen sus manifestaciones, como si estuvieran uno frente al otro.

Por esta razón no puede menospreciarse el rol que desempeñan los elementos técnicos, como la calidad y el tamaño de la imagen que percibe el juez, porque esa es la fuente de la que se obtendrán los elementos para sentenciar en atención a las intervenciones de los sujetos procesales, adminiculadas en sintonía con las condiciones de tiempo, lugar, etc., en las que se ejecutaron.

Aspectos como la postura, ${ }^{27}$ las expresiones faciales (Pease y Pease, p. 85), oculares (Rulicki y Cherny, 2007, p. 36) los gestos con las manos y los brazos, el tono de voz o sistema paralingüístico (Musitu, p. 122), el sistema cronémico o del uso del tiempo (Rulicki y Cherny, p. 41) y el diacrítico o la forma de vestir (Rulicki y Cherny, p. 42) pueden observarse tanto en persona como mediante una pantalla o una proyección de video beam, como ha sucedido en Venezuela, entre otras decisiones, mediante la sentencia número 480 emitida por el Tribunal Primero de Protección del Niño y del Adolescente de la Circunscripción Judicial del Estado Zulia, el veintisiete (27) de abril de 2006; ${ }^{28}$ por el Tribunal Segundo de Protección de Niños, Niñas y Adolescentes de la Circunscripción Judicial del Estado Zulia, por medio de la sentencia 1061 del veintiocho (28) de julio de 2010; ${ }^{29}$ y por el Juzgado Tercero de Protección de Niños, Niñas y Adolescentes de la Circunscripción Judicial del Estado Zulia, por vía de la sentencia 90, dictada el diecisiete (17) de marzo de 2011. ${ }^{30}$

27 Musitu, G. et al. (1993). Psicología de la comunicación humana. Buenos Aires: Lumen, p. 127 y Pease, A. y Pease, B. (2006). El lenguaje del cuerpo. Cómo interpretar a los demás a través de sus gestos. Barcelona: Amat., p. 299.

28 Recuperado de: http://zulia.tsj.gov.ve/DECISIONES/2006/ ABRIL/521-27-6460-480.HTML

29 Recuperado de: http://zulia.tsj.gov.ve/DECISIONES/2010/JULIO/522-28-15705-1061.HTML

30 Recuperado de: http://zulia.tsj.gov.ve/DECISIONES/2011/MARZO/523-17-13326-90.HTML 
Sin embargo, con el uso de la videoconferencia quedarían excluidos aspectos como el tacto, el gusto o el olfato, los cuales no representan limitaciones sensoriales relevantes (Garderes, $p$. 750), aunque excepcionalmente esto pudiera ser necesario, como lo ha venido demostrando, por ejemplo, el desarrollo de la odorología, especialmente en el ámbito criminalístico.

Así mismo, puede resultar exceptuado el sistema proxémico o de las distancias del interlocutor con los demás (Musitu, p. 177), como ocurriría si la transmisión de la videoconferencia se realiza por el declarante sin presencia de otras personas, mas no cuando la declaración debe realizarse desde una oficina pública, entendida en sentido amplio, como ocurrió en la sentencia 1571 dictada el veintidós (22) de agosto de $2001^{31}$ por la Sala Constitucional del Tribunal Supremo de Justicia, donde ordenó, en un proceso de amparo, que se llevara a cabo una videoconferencia desde el Consulado de Venezuela en la ciudad de Vigo, España, decisión que será detallada más adelante, o como lo aconsejan algunos de los autores que han estudiado el tema (Alves, Alves y Pereira, p. 756) a los fines de garantizar la identidad de las partes y que no estén siendo coaccionadas para afirmar o negar un hecho o circunstancia sobre el que tengan una opinión diferente.

Sintetizando este apartado, los cuatro (4) principios que rigen los procedimientos penales en el DLCOPP admiten su consumación telemática.

31 Recuperado de: http://www.tsj.gov.ve/decisiones/scon/agosto/1571-220801-01-1274\%20.HTM
El principio de oralidad exige que el debate sobre los argumentos y las prueba se realice verbalmente y no mediante escritos, lo cual puede lograrse con la videoconferencia, que permite la bidireccionalidad de la comunicación en tiempo real como si las personas estuvieran frente a frente.

El principio de publicidad también es perfeccionable por medio de una audiencia telemática, ya que los presentes en la sala de audiencias donde se proyecte la videoconferencia podrán tomar conocimiento del proceso de la misma manera que si el declarante estuviera presente.

El principio de concentración igualmente se cumple con la videoconferencia porque su uso lejos de entorpecer y retrasar el proceso favorece a la celeridad al facilitar la presencia de quienes deban intervenir, disminuyendo la probabilidad de los diferimientos.

Por último, el principio de inmediación también se materializa en las audiencias telemáticas dado que el juzgador podrá apreciar en quien declara, los mismos que apreciaría en caso de tenerlo de cerca en presencia real.

En consecuencia, la videoconferencia permite que las partes, el defensor, los testigos, expertos e intérpretes puedan comunicarse con el juzgador y viceversa, de modo oral y público.

Por ello, cuando el DLCOPP prevé que a fin de cumplir con los actos comunicación es necesario acceder ante los órganos de administración de justicia penal, tal acceso puede entenderse 
virtual ya que se ha evidenciado que las razones que motivan acudir al tribunal en persona, pueden lograrse usando TIC.

Inclusive, la excepción que admite la validez del acta que documenta la audiencia aun sin las firmas de los intervinientes, bastando la rúbrica del juez y el secretario, coadyuva a la tesis de la validez de la audiencia penal virtual.

Aclarada la posibilidad fáctica y legal de celebrar las audiencias penales en formato electrónico y a distancia, corresponde finalmente verificar si tal actuación gozaría de respaldo constitucional y en caso afirmativo, cuál sería su alcance.

\section{DERECHOS Y GARANTÍAS CONSTITUCIONALES QUE PROMUEVEN Y LIMITAN LA AUDIENCIA PROCESAL PENAL TELEMÁTICA}

La CRBV es la norma suprema y el fundamento del ordenamiento jurídico, a la que todas las personas y los órganos que ejercen el Poder Público y el Poder Popular quedan sujetos (artículo 7).

Texto jurídico que consagra una serie de valores, principios y reglas que sirven de fundamento y límites a la audiencia penal telemática, como se analizará a continuación.

\section{A. Características del proceso jurisdiccional venezolano: artículo 257}

En primer lugar, el artículo 257 define al proceso como un instrumento fundamental para la realización de la justicia, conformado por trámites simples, uniformes y eficaces, mediante un procedimiento breve, oral y público, sin sacrificar la justicia por la omisión de formalidades no esenciales.

Norma que admite y promueve cualquier configuración procedimental que permita lograr el efecto al que está destinado el proceso, como es la realización de la justicia, siempre que el procedimiento creado:

1. Sea simple, vale decir "sencillo, sin complicaciones ni dificultades", 32 característica que puede lograrse mediante el uso de las TIC, dado el desarrollo actual de la informática que permitiría crear un programa computacional intuitivo y adaptado a las características y cultura venezolanas;

2. Sea uniforme, lo que implica igualdad, conformidad o semejanza entre dos o más cosas. ${ }^{33}$ A partir de este principio puede entenderse que todos los procesos deben ser tramitados por procedimientos iguales, salvo que las características especiales de los intereses jurídicos a tutelar, entendidas de forma lógica y no puramente arbitraria, ameriten una conformación especial, en cuyo caso será válido que el legislador haga las diferencias pertinentes; pero también el principio de uniformidad permite entender que todos los tribunales tramitarán los procesos jurisdiccionales mediante los pro-

\footnotetext{
32 Recuperado de: http://lema.rae.es/drae/?val=simple

33 Recuperado de: http://lema.rae.es/drae/?val=uniforme
} 
cedimientos diseñados por el legislador, sin tener la posibilidad de incorporar variaciones entre procesos, salvo la facultad constitucional de control difuso constitucional. Tal conclusión nace de una interpretación histórica que toma en cuenta, a título de Derecho Comparado, la Constitución española de 1812 que consagraba "la uniformidad procesal en todo el Reino" (Lasso Gaite, 1998, p. 3), "la uniformidad de las leyes procesales para toda España" (p. 72) o más específicamente la uniformidad del orden y formalidades del proceso en todos los tribunales del Reino de España. ${ }^{34}$

Como puede advertirse, este principio tampoco excluye el uso de la celebración telemática de las audiencias penales sino que promueve su aplicación uniforme en todo el territorio nacional; sin perjuicio de las pruebas piloto a que hubiera lugar.

3. Esté compuesto por trámites eficaces: Se trata de actos procesales capaces de lograr el fin por el cual fueron creados, que es, como se dijo al principio, la realización de la justicia. De ahí que la celebración de las audiencias penales en un entorno virtual no torne en ineficaz dicho acto, como quedó demostrado al analizar las reglas y principios del DLCOPP. Por el contrario, es posible la intercomunicación del juzgador con plena visualización del comportamiento comunicacional no verbal del declarante del mismo modo que si estuvieran de cuerpo presente.

34 Artículo 244: "Las leyes señalarán el orden y las formalidades del proceso, que serán uniformes en todos los tribunales; y ni las Cortes ni el Rey podrán dispensarlas". Disponible en: http://web.archive.org/ web/20110916105834/http://www.cepc.es/Files/Constitucion1812optimized.pdf
4. Sea breve: El uso de las TIC cuentan entre sus ventajas principales con el ahorro de tiempo, para las partes, expertos, testigos, intérpretes y el tribunal, específicamente respecto de los actos que implican mayores trabas, entre ellos, la comparecencia de las partes y defensores a la sala de audiencias.

Al respecto cabe mencionar la sentencia 314, dictada por la Sala de Casación Penal del Tribunal Supremo de Justicia, el trece (13) de agosto de $2012,{ }^{35}$ mediante la cual se contaron dieciséis diferimientos de audiencias imputables a la víctima y veinticuatro imputables a la acusada, por lo que habían transcurrido ocho años sin pasar de la audiencia preliminar, de ahí que la Sala consideró necesario alertar sobre el perjuicio que le causan a los justiciables y a la propia imagen de la administración de justicia, situaciones como esas que generan pérdida de confianza en las instituciones del Estado.

En los términos expuestos por la decisión citada se evidencia la necesidad de buscar soluciones a este problema; aspecto en el que la videoconferencia surge como una herramienta efectiva para evitar los traslados de las partes a la sede del tribunal, en detrimento del retardo procesal, tal como quedó demostrado con la incorporación del sistema de videoconferencia para la deposición de los expertos en los procesos penales, anunciada por el Tribunal Supremo de Justicia el veintitrés (23) de julio de 2014, ${ }^{36}$ como se indicó antes.

\footnotetext{
35 Recuperado de: http://www.tsj.gov.ve/decisiones/scp/agosto/31413812-2012-A11-1.HTML

36 Recuperado de: http://www.tsj.gov.ve /informacion/notasdeprensa/notasde prensa.asp?codigo $=11970$.
} 
5. Sea oral y público, características que fueron desarrolladas al analizar los principios que rigen los procedimientos penales, a las cuales se remite, siendo necesario precisar que la oralidad y publicidad pueden lograrse en una eventual audiencia telemática ya que la videoconferencia, entendida a título de "comunicación a distancia entre dos o más personas, que pueden verse y oírse a través de una red" ${ }^{37}$ es un instrumento idóneo para la oralidad.

Lo mismo sucede con la publicidad, siempre que se proyecte en una pantalla de tamaño suficientemente amplio para que la audiencia observe la declaración y se utilice un sistema de sonido igualmente adecuado a la sala de audiencia, lo que constituye límites constitucionales a la audiencia virtual la cual no pudiera ser celebrada mediante una equipo al que solo tuviera acceso audiovisual el juez; y por último,

6. No implique sacrificar la justicia por la omisión de formalidades no esenciales, ya que el proceso debe buscar la justicia "más allá de adaptarse fielmente a la positivación jurídica" (Zerpa Aponte, p. 173).

Al respecto, la presencia real de todos los sujetos procesales en la Sala de Audiencias no siempre constituye una formalidad esencial, ya que los fines de la inmediación pueden lograrse completamente con la videoconferencia, teniendo en cuenta los requerimientos técnicos y las limitaciones sensoriales (imposibilidad de uso de los sentidos del tacto, olfato y gusto) expli-

37 Recuperado de: http://lema.rae.es/drae/?val=videoconferencia cados previamente. En este caso actuaría como limitación constitucional el uso de la videoconferencia cuando fuera necesaria la presencia real para que el juez lleve a cabo comprobaciones que impliquen el uso del olfato, del tacto o del gusto, pero en los demás casos, donde solamente sea necesario el uso de la vista y del oído, como ocurrirá normalmente, la audiencia virtual permitiría cumplir con esta norma constitucional.

\section{B. Derecho a la igualdad, en especial de quienes residen a mayor distancia de las sedes judiciales: artículos 2 y 21}

El artículo 2 propugna la igualdad como valor superior del ordenamiento jurídico venezolano, desarrollándolo en el artículo 21 mediante: a. La proscripción de discriminaciones que tengan por objeto o por resultado anular o menoscabar el reconocimiento, goce o ejercicio en condiciones de igualdad, de los derechos y libertades de toda persona; b. La imposición de garantizar legalmente las condiciones jurídicas y administrativas para que la igualdad ante la ley sea real y efectiva; c. Adoptando medidas positivas a favor de personas o grupos que puedan ser discriminados, marginados o vulnerables; d. Protegiendo especialmente a aquellas personas que por alguna de las condiciones antes especificadas, se encuentren en circunstancia de debilidad manifiesta; y e. Sin reconocer títulos nobiliarios ni otros privilegios más allá de las consideraciones diplomáticas.

Esta norma abona al uso de la videoconferencia en las audiencias penales puesto que mediante 
ella se favorece el acceso a la justicia, en especial de quienes se encuentran más alejados de las sedes judiciales. Y es que "para que podamos hablar de un debido proceso, este no debe permitir situaciones de desigualdad frente a los diversos actos procesales" (Zerpa Aponte, p. 174), como pareciera suceder en materia de apelación, en los casos de radicación o sustracción de la causa y atribución de la competencia a un tribunal de otro circuito judicial penal con ocasión del avocamiento, y, con mayor razón, al ejercer el recurso de casación, las cuales constituyen situaciones donde la lejanía del tribunal implica desventajas que se evidencian al comparar las distancias y gastos menores en que deben incurrir quienes residen más cerca de la sede del juzgador.

En efecto, el deber constitucional de garantizar mediante la ley las condiciones jurídicas y administrativas para que la igualdad sea real y efectiva, avalan el uso de las TIC en el proceso, donde queda comprendida la videoconferencia en la celebración de las audiencias penales.

Aunado a ello, la imposición de adoptar medidas legales positivas a favor de personas o grupos que puedan ser discriminados, marginados o vulnerables sirve de fundamento para implementar el uso de la videoconferencia para aqueIlas personas a quienes se les dificulte, por cualquier razón, trasladarse hasta la sede judicial.

En tal sentido, basta pensar en la planificación y gastos que supone acudir a una audiencia de casación en el Tribunal Supremo de Justicia por parte de quienes residen fuera del Área Metro- politana de Caracas, con el riesgo de su posible suspensión.

La preocupación aludida tuvo ocasión de elevarse al conocimiento de la Sala Electoral, quien mediante la sentencia 95 del catorce (14) de julio de 2004, declaró improcedente la solicitud del recurrente de realizar sus actos procesales mediante videoconferencia.

El fundamento de la respuesta se centró en que por regla general, la actuación de las partes se rige por el principio de inmediación, en este caso, en la sede del Tribunal y en presencia del Secretario, lo contrario, añadió, sería subvertir formalidades esenciales del proceso por suplir las eventuales dificultades de acceso o traslado de los litigantes.

En concreto, con esta decisión, la Sala manifestó que no procedía el uso de la videoconferencia para que alguna de las partes intervenga en juicio porque la ley no lo preveía, y así puede comprobarse revisando la ley Orgánica del Tribunal Supremo de Justicia de 2004, que ya tenía casi un mes de vigencia cuando fue solicitada la tramitación del proceso mediante videoconferencia.

Seis años más tarde, con la reforma de la Ley Orgánica del Tribunal Supremo de Justicia de 2010, el único aparte del artículo 85 prevé que el máximo tribunal de la República “en cada una de sus Salas favorecerá la utilización de las herramientas tecnológicas disponibles para la sustanciación de las causas sometidas a su conocimiento, para la implementación de trámites transparentes y expeditos". 
Tal vez, esta norma, aunada al criterio sobre la posibilidad de usar la videoconferencia, expuesto por la Sala Constitucional del Tribunal Supremo de Justicia en la sentencia 1571 del veintidós (22) de agosto de 2001, 38 llevó a la Sala a dictar la decisión 1 de 2011, ${ }^{39}$ a la que se hizo alusión previamente, ordenando valerse de la videoconferencia para resolver un amparo contra la sentencia que acordó a un ciudadano, la custodia de un niño que se encontraba en Vigo, España.

En esa ocasión, la Sala indicó realizar una videoconferencia desde el Consulado de Venezuela para que pudiera escuchar al niño y así garantizar su derecho a ser oído sobre los asuntos que sean de su interés, previo a la celebración de la audiencia constitucional.

Aunque la videoconferencia nunca llegó a realizarse porque la accionante desistió de la pretensión siendo homologada mediante el fallo 608 del veintitrés (23) de mayo de 2013, ${ }^{40}$ la importancia de este fallo radica en que se ratifica la posibilidad de emplear la videoconferencia para cumplir un acto procesal.

38 Recuperado de: http://www.tsj.gov.ve/decisiones/sco n/agosto/1571-220801-01-1274\%20.HTM

39 Recuperado de: http://www.tsj.gov.ve/decisiones/scon/enero/01-27111-2011-09-0912.HTML

40 http://www.tsj.gov.ve/decisiones/scon/mayo/608-23513-2013-090912.HTML

\section{Derecho al bienestar y garantía del cumplimiento de los principios, derechos y deberes reconocidos y consagrados en la constitución: artículo 3}

La CRBV prevé como fines esenciales del Estado la defensa y el desarrollo de la persona, la promoción de la prosperidad y bienestar del pueblo y la garantía del cumplimiento de los principios, derechos y deberes reconocidos y consagrados en ella.

Sobre la base de tales deberes cabe fundar el uso procesal de las TIC, puesto que con ellas se facilita la defensa de la persona, su bienestar y el cumplimiento de la Constitución, que garantiza el acceso a la justicia.

En consecuencia, al incluir nuevas vías de acceso a la jurisdicción se facilita la defensa y el bienestar de los ciudadanos, quienes requerirán menor inversión de tiempo y dinero para obtener la tutela de sus intereses jurídicos.

Así mismo, la implementación de la videoconferencia en las audiencias penales, que permitan a los intervinientes actuar del mismo modo que si estuvieran en presencia real, constituye una garantía del cumplimiento de los principios, derechos y deberes reconocidos y consagrados en la Constitución.

\section{Goce de los derechos humanos: artículo 19}

El acceso a la justicia es un derecho humano establecido expresamente en la CRBV; por con- 
siguiente, cuando el Estado le garantiza a toda persona el goce y ejercicio irrenunciable, indivisible e interdependiente de los derechos humanos, está asumiendo el compromiso de valerse de los medios necesarios para garantizar ese acceso, dentro de las capacidades económicas del Estado y conforme al ordenamiento jurídico.

Por este motivo, la celebración virtual de las audiencias penales en tanto que medio factible para acceder a la justicia, también encontraría respaldo en esta norma, siempre que se cumpla con las limitaciones constitucionales que se han enumerado y las que se indicarán a continuación.

\section{E. Primacía de los tratados sobre derechos humanos más favorables: artículo 23}

Los tratados internacionales sobre derechos humanos, suscritos y ratificados por Venezuela, prevalecen en el orden interno, en la medida en que sean más favorables, siendo de aplicación inmediata y directa por los órganos del Poder Público.

En este sentido, cabe traer a colación el Estatuto de Roma de la Corte Penal Internacional, suscrito el catorce (14) de octubre de 1998 y ratificado el siete (7) de junio de 2000. Conforme al referido instrumento de derecho es posible " presentar pruebas por medios electrónicos u otros medios especiales" (numeral 2 del artículo 68), sin discriminación de ningún medio probatorio como la declaración de las víctimas y de los testigos, reiterándose respecto de estos últimos, que podrán declarar "por medio de una grabación de vídeo o audio" (numeral 2 del artículo 69).

Adicionalmente, el instrumento internacional bajo análisis permite que el acusado, observe el proceso y dé instrucciones a su defensor desde fuera de la sala de audiencias, "utilizando, en caso necesario, tecnologías de comunicación... en circunstancias excepcionales, después de que se haya demostrado que no hay otras posibilidades" (numeral 2 del artículo 63).

Partiendo del texto transcrito puede evidenciarse que el Estatuto de Roma prevé la posibilidad de evacuar testigos y declaraciones de las víctimas por medios electrónicos, así como también que el acusado participe del mismo modo en el procedimiento previsto en el Estatuto, pero no en todo tipo de proceso; es decir, no se está ante una regulación genérica que consagre el derecho de todo acusado, víctima o testigo a participar en un proceso jurisdiccional mediante TIC, puesto que en ese caso, el derecho a la audiencia telemática sería poco discutible. En realidad, el tratado referido contiene derechos para un procedimiento preciso, el que se sigue ante la Corte Penal Internacional, por lo que viene a sumarse al resto de las leyes nacionales en las que se recoge el uso de la tecnología en el ámbito procesal, ${ }^{41}$ sin que ello pueda servir de fundamento directo para exigir la celebración telemática de las audiencias penales.

41 la Ley Orgánica Procesal del Trabajo de 2002; la Ley de Protección de Víctimas, Testigos y demás Sujetos Procesales (LPVTSP) de 2006; la Ley Orgánica para la Protección de Niños, Niñas y Adolescentes (LOPNNA) de 2007; la Ley Orgánica de la Jurisdicción Contencioso Administrativa de 2010; la Ley Orgánica del Tribunal Supremo de Justicia de 2010 (LOTSJ); y la Ley Orgánica contra la Delincuencia Organizada y el Financiamiento del Terrorismo de 2012 (LODOFT). 


\section{F. Deber de cumplir la constitución y nulidad de los actos que violen los derechos garantizados en ella: artículos 25 y 131}

En aras de dotar de efectos prácticos su supremacía, la Constitución establece, por una parte, el deber de los particulares de acatarla al igual que al resto del ordenamiento jurídico, y por otra parte, determina la nulidad de todo acto dictado en ejercicio del Poder Público que viole o menoscabe los derechos garantizados por ella y la ley.

Con tal previsión normativa la celebración virtual de la audiencia de juicio sería nula si violara o menoscabara derechos constitucionales y legales, lo cual correspondería evaluar en el caso concreto, puesto que su celebración per se no impide el ejercicio de derecho alguno como se pudo demostrar en este análisis.

\section{G. Principio de legalidad: artículos 137 y 253}

Los órganos jurisdiccionales, al formar parte del Poder Público, quedan sujetos en sus actividades a la Constitución y la ley. Por esta razón, aplicando estrictamente el ordenamiento jurídico, solamente sería válido celebrar audiencias telemáticas cuando la ley o la Constitución lo previeran, cumpliendo de esta manera con el principio de legalidad adjetiva.

Sin embargo, la previsión en referencia no necesariamente tiene que ser expresa, sino que ella podría surgir de la interpretación de la ley, contextualizada en los avances tecnológicos con los que convivimos y que constituyen máximas de experiencia.

Por ello, cuando la Constitución exige procesos tramitados mediante procedimientos orales, así como también lo hace el DLCOPP, el cual a su vez insiste en la presencia ante el juez, en el interrogatorio y la emisión de declaraciones, puede entenderse que en todos esos actos se incluye su verificación real y virtual, puesto que ambos casos permiten lograr los resultados esperados.

Por tanto, es factible admitir la audiencia telemática a partir de la letra de la ley, que es la lectura que se propone darle al DLCOPP como lo hizo el Tribunal Supremo de Justicia a fin de incorporar el uso de videoconferencia para facilitar la intervención judicial de los expertos forenses en juicio.

\section{H. Derecho de acceso a los órganos de justicia: artículo 26}

Uno de los preceptos más importantes para admitir la audiencia penal telemática y en general para el uso de las TIC y en el proceso jurisdiccional es el derecho de acceso a los órganos de administración de justicia para hacer valer sus derechos e intereses, a la tutela efectiva de los mismos y a obtener con prontitud la decisión correspondiente.

Esta norma obliga al Estado a permitir, en la práctica, el acceso de todos los ciudadanos a los tribunales para satisfacer la necesidad de justicia que corresponde a estos órganos del Poder 
Público. Ello implica valerse de todos los medios pertinentes para cumplir tal fin y en especial de aquellos que permitan recibir pronta respuesta, situación que genera un contexto propicio para el uso de la tecnología.

De acuerdo con este postulado, el Estado garantizará una justicia:

1. Gratuita: La presencia telemática en el tribunal es menos costosa que la real, en especial cuando la comparecencia supone traslados, alimentación, estacionamiento y pernocta, entre otros gastos. A tal efecto, el artículo 108 constitucional consagra que el Estado garantizará redes de informática con el fin de permitir el acceso universal a la información, derivando una opción de acceso gratuito a distancia para los justiciables, en especial para quienes no cuenten con los medios económicos suficientes para trasladarse hasta la sede del tribunal competente;

2. Accesible: Al permitir el acceso virtual a la justicia, adicionalmente al real, se garantiza en mayor medida la presencia de los sujetos procesales en el proceso. Lo importante es la apertura de opciones que cada quien elegirá si decide usarlas y cuándo usarlas;

3. Imparcial, autónoma, independiente y responsable: Estas características no se refieren al procedimiento, de ahí que sea impertinente su desarrollo a efectos de este análisis;

4. Idónea: Supone que la justicia sea "adecuada y apropiada para algo", ${ }^{42}$ siendo ese "algo"

42 Recuperado de: http://lema.rae.es/drae/?val=id\%C3\%B3neo la tutela efectiva de intereses jurídicos. En este sentido, el uso de las TIC en las audiencias penales permite cumplir con todos los derechos, cargas, deberes y obligaciones que corresponden, como se planteó con anterioridad;

5. Transparente: La audiencia virtual no es una actividad que se realiza a escondidas del público y a la que únicamente accede el juzgador, por el contrario, puede ser tanto o más pública que la audiencia virtual, según lo decida el legislador en el procedimiento previsto al efecto;

6. Equitativa: La celebración de la audiencia virtual no beneficia a una de las partes en detrimento de la otra, sino que le permite ambas, valerse de ella en igualdad de condiciones, ejerciendo los mismos derechos que le corresponde a cada una en la audiencia en presencia real; $y$,

7. Expedita, sin dilaciones indebidas, sin formalismos o reposiciones inútiles: Al emplear la telemática en las audiencias del proceso penal se disminuyen las probabilidades de diferimiento a causa de la inasistencia de las partes dado que eliminando el traslado, se facilita el acceso judicial y con ello es más factible que el proceso sea expedito.

\section{La libertad personal: Artículo 44 (numeral 1)}

El derecho constitucional a la libertad personal supone que ninguna persona pueda ser arrestada o detenida sino en virtud de una orden judicial, salvo que se tratare de un caso de flagrancia, en cuyo caso será llevada ante una autori- 
dad judicial en menos de cuarenta y ocho horas contadas desde la detención.

La norma constitucional impone que el sujeto detenido sin orden judicial sea llevado ante una autoridad judicial, de modo que la interpretación literal exige la presencia real ante el juzgador; no obstante, la interpretación de la ley conforme al estado actual de la civilización permite que el sujeto sea llevado ante el juez mediante el uso de TIC, ya que en ambos casos es posible cumplir las finalidades que imponen su presentación; en todo caso, no se le pudiera obligar a presentarse virtualmente si el procesado solicita ser llevado de modo real ante el juez, constituyendo la voluntad del imputado un límite constitucional a la audiencia virtual.

\section{J. Privacidad de las comunicaciones: artículo 48 y 60}

La Constitución también protege las comunicaciones privadas en todas sus formas, y la comunicación del acusado con su defensor, es una de ellas. ${ }^{43}$ Esta situación resulta técnicamente posible de ahí que no se excluya el uso de la telemática en las audiencias penales.

Igualmente, el derecho a la protección del honor, vida privada, intimidad, propia imagen, confidencialidad y reputación de quienes decla-

El artículo 6 de la Ley Especial Contra Delitos Informáticos de 2001 sanciona con pena de prisión a quien acceda indebidamente a los sistemas informáticos (artículo 6) y a quien viole la privacidad de las comunicaciones (artículo 21), mientras que el artículo 189 de la Ley Orgánica de Telecomunicaciones de 2011 remite a "la ley especial que rija la materia" para castigar a quien intercepte, interfiera, copie o divulgue, ilegalmente, el contenido de las comunicaciones. ren en un proceso penal, piénsese en niños y adolescentes o víctimas en general de delitos sexuales, puede salvaguardarse en una audiencia virtual o telemática, cuya regulación legal deberá considerar estos derechos.

\section{K. El debido proceso: artículo 49}

El debido proceso se compone de una serie de derechos, de los que corresponde analizar dos (2) de ellos, a fin de precisar la posibilidad jurídica de celebrar las audiencias penales en formato electrónico. Se trata del derecho a la defensa (numerales 1 y 3) y al juez natural (numeral 4).

De acuerdo con la norma suprema y fundamental del ordenamiento jurídico, la defensa y la asistencia jurídica son derechos inviolables en todo estado y grado de la investigación y del proceso, previsión que se refiere al derecho del imputado de contar con un abogado que lo defienda, por lo que el ejercicio de la defensa, al tratarse de una labor que se materializa con la palabra, no se ve trabado porque la audiencia tenga lugar aplicando la telemática.

No obstante, si fuera necesaria alguna actividad defensiva que requiera la presencia real, sería inconstitucional la audiencia virtual al dejar de ser un medio adecuado para ejercer su defensa. Situación que deberá determinarse en cada caso concreto.

Por otra parte, el derecho a la defensa garantiza que toda persona sea oída en cualquier clase de proceso, con las debidas garantías y dentro del plazo razonable determinado legalmente, por 
un tribunal competente, independiente e imparcial, establecido con anterioridad.

La garantía constitucional se refiere al derecho a ser oído, lo que es perfectamente ejecutable mediante una audiencia telemática como se demostró en el capítulo anterior, siempre que se garantice el ejercicio de los mismos derechos ejercitables en caso de ser practicada en presencia real.

En lo concerniente al juez natural, la Constitución garantiza el derecho de toda persona a ser juzgada por sus jueces naturales con las garantías establecidas en esta Constitución y en la ley. Conforme a esta norma, si en el desarrollo de la audiencia telemática llegare a vulnerarse alguna garantía constitucional o legal esta sería nula. Así por ejemplo, si quien accede a la audiencia virtual no puede ver quién lo está juzgando y por tanto desconoce la identidad de quien la juzga, o en caso de que la audiencia virtual se practicare ante un tribunal de excepción o incluso, por una comisión creada para tal efecto, dicha audiencia sería tan nula como lo sería la audiencia en presencia real, en la que se incurra en los mismos vicios.

\section{Derecho de acceso a la información: artículo 110}

Por último, la norma fundamental para la incorporación de TIC en las actividades del Poder Público, entre ellas, para dotar de fundamento constitucional a la audiencia telemática, es el artículo 110 de la Constitución.
Conforme al referido precepto normativo, el Estado reconocerá el interés público de la ciencia, la tecnología, el conocimiento, la innovación y sus aplicaciones y los servicios de información necesarios por ser instrumentos fundamentales para el desarrollo económico, social y político del país, donde queda incluida la jurisdicción.

De este modo, el Estado reconoce la importancia de usar TIC en el ejercicio de sus funciones, entre ellas la jurisdiccional, para lograr su desarrollo integral. Por esta razón, las audiencias penales virtuales cuentan con asidero constitucional, siendo tal su importancia que para el fomento y desarrollo de esas actividades, el Estado destinará recursos suficientes, de donde se concluye que está garantizado el equipamiento de los tribunales así como la inversión para la formación del recurso humano que realizará las audiencias bajo esta modalidad.

No obstante este compromiso estatal, la misma Constitución reconoce el deber ciudadano de coadyuvar con el funcionamiento del Estado (artículo 135) por lo que aquellos costos en los que incurran las partes para participar en la audiencia virtual, siempre que no impliquen un deber del Estado traspasado como carga a los particulares, encuentran respuesta en el precepto referido.

Concretando este último epígrafe, admitido el carácter supremo y fundamental de la CRBV, ninguna norma del ordenamiento jurídico o acto jurídico serán válidos si menoscaban los derechos y garantías constitucionales, por ello la audiencia procesal penal virtual o telemática goza 
de fundamento constitucional porque: 1. Garantiza los postulados de la oralidad, propende a la brevedad y publicidad de la administración de justicia; 2. Permite el ejercicio de la acción jurisdiccional en igualdad de condiciones para todos los ciudadanos; 3. Incrementa el bienestar social al facilitar el acceso a la justicia, derechos humano que protegido por la norma fundamental; 4. Es acorde con las previsiones de tratados internacionales y con normas procesales de reciente data con visión realista y actualizada respecto de la forma de vida contemporánea; 5. Permite cumplir la Constitución y la ley; 6. A partir de una interpretación actualizada de los modos de interacción social no riñe con el principio de legalidad; 7. Hace más eficaz el acceso a la justicia al incorporar nuevas formas de presentarse ante el juzgador; y 8. El Estado reconoce la importancia de usar TIC en el ejercicio de sus funciones, entre ellas la jurisdiccional, para lograr su desarrollo integral.

Pero la validez de la audiencia dependerá de la voluntad del acusado, al menos cuando se trate de la audiencia de presentación, ya que el detenido tiene derecho a ser llevado ante una autoridad judicial, lo que sugiere conforme a la interpretación más favorable al reo, entender que dicha presencia debe ser real y no solamente virtual.

Así mismo, la audiencia virtual encuentra como límites constitucionales: 1. La privacidad de las comunicaciones, por lo que deberá garantizarse que las declaraciones que se emitan y la eventual comunicación a distancia con la defensa de modo privado, será garantizada por el tribunal; 2. La necesidad de alguna actividad defensi- va que requiera la presencia real, lo cual será ponderado por el juez en cada caso concreto; y 3. El derecho del acusado a ver y oír quién lo está juzgando, interrogando, reconociendo, etc., de la misma manera que si estuviera presente; siendo necesario, además, a fin de garantizar la publicidad, que el sistema de proyección de la imagen, reproducción del sonido y calidad de la conexión a Internet, sean adecuados para permitir la publicidad y recepción de la declaración, a todos los sujetos en videoconferencia, como si estuvieran en la sala de audiencias.

\section{CONCLUSIONES}

El DLCOPP no prevé normas de aplicación general que impida la práctica virtual de los veintitrés (23) tipos de audiencias previstas en el DLCOPP, cuya normativa específica tampoco excluye expresamente el uso de las TIC, situación que por el contrario, es fomentada por el DLMDFE y la Ley de Infogobierno al regular el uso de las TIC en el ejercicio del Poder Público.

Lo anterior se puede observar tanto en los catorce (14) tipos de audiencias, en los que únicamente existe la posibilidad de exponer y debatir argumentos de hecho y derecho, como en los otros nueve (9) tipos de audiencias en los que además de participar debatiendo sobre sus afirmaciones de hechos y fundamentos de derecho, las partes discutirán sobre los elementos de convicción o pruebas, según el caso.

En cada una de esas oportunidades, el DLCOPP establece una serie de actos de comunicación 
bidireccionales, entre el tribunal y los sujetos procesales a quienes la ley les reconoce cargas, derechos, deberes y obligaciones, en presencia del juez, quien junto al alguacil goza de potestades disciplinarias respecto de los presentes en la sala de audiencia, los cuales serán documentados en actas firmadas por los presentes, salvo las excepciones de ley.

Siendo el caso que tales actuaciones pueden verificarse en una audiencia virtual, cumpliendo con las reglas adjetivas y también con los principios procedimentales previstos en el mismo DLCOPP.

Así, el principio de oralidad, según el cual la discusión argumentativa y sobre las pruebas debe producirse mediante la palabra hablada, puede cumplirse usando un sistema de videoconferencia, el cual permite la bidireccionalidad de la comunicación en tiempo real como si las personas estuvieran próximas en el plano espacio temporal.

Lo mismo ocurre con: 1. El principio de publicidad, puesto que los presentes en la sala de audiencias donde se proyecte la videoconferencia podrán observar directamente el proceso como si el declarante estuviera presente; 2. El principio de concentración, dado que la videoconferencia beneficia la celeridad al facilitar que los sujetos que deban participar puedan verse, hablarse y escucharse, pero sin las complicaciones que trae consigo el traslado hasta el tribunal; y 3. El principio de inmediación, porque el administrador de justicia tendrá la posibilidad de percibir el discurso a plenitud, tanto en su contenido como en su forma, al igual que si el sujeto que declara estuviera de cuerpo presente en la sede del órgano judicial.

Como derivado de lo expuesto, la videoconferencia permite que las partes, el defensor, los testigos, expertos e intérpretes puedan comunicarse con el juzgador y viceversa, de modo oral y público, lo que justifica que la exigencia de presencia ante el juzgador a la que se refiere el DLCOPP para cumplir con los actos comunicación, pueda entenderse de modo virtual ya que las razones que motivan acudir al tribunal en persona para conocer las declaraciones y el comportamiento de quienes declaran, pueden alcanzarse utilizando TIC.

Inclusive, la excepción que admite la validez del acta que documenta la audiencia aun sin las firmas de los intervinientes, bastando la rúbrica del juez y el secretario, coadyuva a la validez de la audiencia penal virtual.

Aclarada la posibilidad fáctica y legal de celebrar audiencias penales virtuales, también se evidencia su constitucionalidad, puesto que su uso pudiera encontrar, inclusive, promoción en las normas supremas del ordenamiento jurídico al permitir cumplir con las exigencias de la oralidad y publicidad, facilitando la celeridad procesal y el ejercicio de la acción jurisdiccional para todos los ciudadanos, con lo que aumenta el bienestar social.

Así mismo, su implementación encuadra con la normativa más reciente hasta la fecha y aún en caso de falta de regulación especial, es posible 
implementarla de inmediato, como se hecho en la práctica, siguiendo una interpretación realista de la manera en la que convivimos actualmente con la tecnología, situación que se le impone reconocer al Estado en la propia Constitución.

No obstante, la norma suprema del ordenamiento jurídico también crea límites a la audiencia telemática, como son: la voluntad del imputado privado de libertad de ser llevado en presencia real ante un órgano jurisdiccional; la publicidad de las declaraciones circunscrita al público de la sala de audiencia y de las comunicaciones entre el imputado y la defensa; la ejecución de alguna actividad que solamente pueda ejecutarse de cuerpo presente ante el juez; y el derecho del imputado de visualizar y escuchar al juzgador, víctima, fiscal del Ministerio Público, testigos, expertos y en general, que todos los intervinientes puedan percibirse entre sí, como si estuvieran en un mismo lugar.

\section{Referencias}

Alves, F., Alves M y Pereira, T. (2011). El uso de la videoconferencia en los procedimientos penales: los dos lados de una misma moneda. Memorias del XV Congreso Iberoamericano de Derecho e Informática. Argentina, eldial.com.

Amoni, G. (2012). De los procedimientos judiciales orales a los electrónicos. Fodertics, estudios sobre Derecho y Nuevas Tecnologías. España: Andavira.
Amoni, G. (2013). El uso de la videoconferencia en cumplimiento del principio de inmediación procesal. Revista IUS, 31. Puebla: Instituto de Ciencias Jurídicas de Puebla.

Amoni, G. (2014). Análisis jurisprudencial sobre la prueba de testimonial mediante videoconferencia en Venezuela. Fodertics II: hacia una justicia 2.0. España: Ratio legis.

Calamandrei, P. (2000). La casación civil. Argentina: EBA.

Devis Echandía, H. (1993). Teoría General de la prueba judicial. Bogotá: Dike.

Fairén Guillén, V. (1990). Doctrina general del Derecho procesal, hacia una teoría y ley procesales generales. España: Bosch.

Garderes, S. (2002). El principio de inmediación y las nuevas tecnologías aplicadas al proceso, con especial referencia a la videoconferencia. En XVII Jornadas iberoamericanas XI Jornadas uruguayas de Derecho Procesal. Fundación de Cultura Universitaria, Montevideo.

Guasp, J. (1962). Derecho Procesal Civil. Instituto de Estudios Políticos, Madrid-España.

http://jca.tsj.gov.ve

http://web.archive.org

http://www.rae.es

http://www.tsj.gov.ve 
Landoni, Á. (2002). Incidencia de las nuevas tecnologías en el proceso jurisdiccional, con especial análisis de las cuestiones referentes a la prueba, a las medidas cautelares y a la comunicaciones procesales. En XVII Jornadas iberoamericanas XI Jornadas uruguayas de Derecho Procesal. Uruguay, Fondo de Cultura Universitaria.

Lasso Gaite, J. (1998). Crónica de la codificación española, procedimiento civil. Madrid: Ministerio de Justicia.

Lauría, C. (2000). La prueba en el juicio oral. La aplicación efectiva del COPP, terceras jornadas de Derecho Procesal Penal. Caracas: UCAB.

Montero Aroca, J. (2004). Introducción. Derecho Jurisdiccional I, parte general, 13. ${ }^{a}$ ed. España: Tirant lo Blanch.

Montero Aroca, J. (2004). Los principios del procedimiento, forma y formalismo. Derecho Jurisdiccional I, parte general (13 ${ }^{\mathrm{a}}$ Ed.) España: Tirant Lo Blanch.

Montero Aroca, J. (2004). Naturaleza del proceso. Derecho Jurisdiccional I, parte general, $13^{\mathrm{a}}$ edición, Valencia.

Musitu, G. (1993). Psicología de la comunicación humana. Buenos Aires: Lumen.

Otero Parga, M. (1999). Valores constitucionales, introducción a la filosofía del derecho, axiología jurídica. España: Universidad Santiago de Compostela.
Ortiz-Ortiz, R. (2004). Teoría General del Proceso, $2^{a}$ edición, Caracas: Frónesis.

Pease, A. y Pease, B. (2006). El lenguaje del cuerpo, cómo interpretar a los demás a través de sus gestos. Barcelona: Amat.

Pérez, E. (2004). Los recursos en el proceso penal venezolano. Valencia, Venezuela: Vadell hermanos.

Prieto-Castro, L. (1989). Derecho Procesal Civil. $5^{\mathrm{a}}$ ed., España: Tecnos.

Puppio, V. (2001). Teoría General del Proceso ( $3^{\mathrm{a}}$ ed.). Caracas: UCAB.

Rengel-Romberg, A. (2007). Tratado de Derecho Procesal Civil Venezolano, teoría general del proceso, (T. II, 13 ${ }^{\mathrm{a}}$ ed.). Caracas: Organización Gráficas Capriles.

Robert, A. (2007). Teoría de la argumentación jurídica, (Atienza, M. y Espejo, I. Traductores). España, Centro de Estudios Políticos y Constitucionales.

Rulicki, S. y Cherny, M. (2007). Comunicación no verbal. Buenos Aires: Granica.

Salazar, R. (2001). Principios informadores del nuevo proceso penal. Primeras Jornadas de Derecho Procesal Penal, el nuevo proceso penal. Caracas: UCAB.

Schorbohm, H. y Lossing, N. (1995). El Proceso penal, principio acusatorio y oralidad en Alemania. Propuestas para la reforma del pro- 
ceso penal venezolano. Barquisimeto: Colegio de Abogados del Estado Lara.

Vecchionacce, F. (2001). El juicio oral y la posición jurídica del imputado. Primeras Jornadas de Derecho Procesal Penal, el nuevo proceso penal. Caracas: UCAB.
Zerpa Aponte, A. (2007). Revisión del concepto de "Debido Proceso" en su relación con el proceso penal venezolano. Debido proceso y medidas de coerción personal, $X$ Jornadas de Derecho Procesal Penal, Caracas, UCAB. 